\title{
Adsorption of Divalent Transition Metal Ions with a Chelating Agent on Octadecyl Silica Gel
}

\author{
Masamitsu IIYAma, *† Syunichi Oshima,* Hisao Kokusen,* Masami Sekita,** \\ Shigekazu Tsurubou, *** and Yu Komatsu* \\ *Department of Environmental Chemistry, College of Environmental Engineering and Architecture, \\ Kanazawa Institute of Technology, 7-1 Ohgigaoka, Nonoichi, Ishikawa 921-8501, Japan \\ **National Institute for Materials Science, 1-1 Namiki, Tsukuba, Ibaraki 305-0044, Japan \\ ***Department of Chemistry, School of Dentistry, Asahi University, 1851 Hozumi, \\ Hozumi-cho, Motosu-gun, Gifu 501-0296, Japan
}

\begin{abstract}
This investigation looked at the extraction ability of divalent transition metal ions onto an octadecyl silica gel (C18g) with a 4,4-trifluoro-1-(2-thienyl)-1,3-butadione (TTA) chelating agent. A method of retaining TTA onto C18g (TTA-C18g) was developed in order to adsorb the metal ions. The difference in the half-adsorption and half-extraction $\mathrm{pH}$ values between transition metals $\mathrm{Ni}^{2+}-\mathrm{Co}^{2+}$ was found to be 0.7 in this system. This is better than previously published results of 0.3 for the conventional extraction method using TTA in nitrobenzene. More than $96 \%$ of the metal ions in aqueous solution could be adsorbed onto TTA-C18g. Our system, which has no organic phase, can achieve a better removal or separation of transition metal ions than the conventional solvent-extraction methods using TTA in toluene or nitrobenzene.
\end{abstract}

(Received July 5, 2004; Accepted August 31, 2004)

The 4,4,4-trifluoro-1-(2-thienyl)-1,3-butadione (TTA) used in to toluene solvent-extraction (SE) technique is known to be one of the most effective methods to remove or separate toxic metal ions. ${ }^{1}$ We have developed a new solvent-extraction method to efficiently remove metal ions using an octadecyl silica gel (C18g) together with TTA (SE-C18g). ${ }^{2}$ This method showed an increase in the extraction ability of the metal ions compared with SE. The extraction mechanism of this system involves to adsorption of the extracted metal chelate in the organic phase onto $\mathrm{C} 18 \mathrm{~g} .^{3}$ Because the adsorption reaction is affected by the affinity of $\mathrm{C} 18 \mathrm{~g}$ to the solvent, it is necessary to use a lower polarity organic solvent, such as toluene. A system has been developed that has no organic solvent, by retaining the TTA molecule directly onto $\mathrm{C} 18 \mathrm{~g}$ (TTA-C18g). However, the new TTA-C $18 \mathrm{~g}$ particles were found to aggregate together in the aqueous solution due to their hydrophobicity. Hence, a quantitative analysis of metal ion adsorption could not be performed. To prevent aggregation, the C18g particle size was increased. Larger TTA-C18g particles are less likely to aggregate, and are considered to have better adsorption ability. This paper reports on a new method to remove and separate metal ions, without the use of organic solvents, by using large TTA-C18g particles.

\section{Experimental}

\section{Reagents and apparatus}

The starting materials were silica gel (Wako Pure Chemical

To whom correspondence should be addressed.

E-mail: m.iiyama@venus.kanazawa-it.ac.jp
Industries, 1 - $2 \mathrm{~mm}$ particle size) and TTA (Dojindo Laboratories). All other reagents were of analytical grade. Deionized water was prepared by a MilliQ Gradient A10 MILLIPORE and used throughout.

An inductively coupled argon-plasma atomic emission spectrometry (ICP-AES, VARIAN VISTA-PRO) apparatus was used to determine to metal ion concentration in aqueous solution. The $\mathrm{pH}$ values of aqueous solutions were measured by a $\mathrm{pH}$ meter (HORIBA F-21) equipped with a glass electrode.

\section{Preparation of TTA-C18g}

Silica gel was crushed and sieved to a size of $0.50-1.0 \mathrm{~mm}$. The $\mathrm{C} 18 \mathrm{~g}$ was synthesized according to a published method. ${ }^{4}$ In order to synthesize TTA-C $18 \mathrm{~g}, 50 \mathrm{~cm}^{3}$ of toluene containing $0.5 \mathrm{~mol} \mathrm{dm}^{-3}$ TTA was added to $10 \mathrm{~g}$ of $\mathrm{C} 18 \mathrm{~g}$. After standing for $24 \mathrm{~h}$ at $277 \mathrm{~K}$, the mixed solution was filtered, washed with deionized water and dried at room temperature under a vacuum.

\section{Adsorption experiment of divalent transition metal ions}

Aqueous solutions were prepared containing $1.0 \times 10^{-4} \mathrm{~mol}$ $\mathrm{dm}^{-3}$ metal ions $\left(\mathrm{Co}^{2+}, \mathrm{Ni}^{2+}\right.$ or $\left.\mathrm{Cu}^{2+}\right), 0.1 \mathrm{~mol} \mathrm{dm}^{-3}$ sodium perchlorate and $2.0 \times 10^{-2} \mathrm{~mol} \mathrm{dm}^{-3}$ of a buffer agent (chloroacetic acid or acetic acid). A $20 \mathrm{~cm}^{3}$ aliquot of each solution, along with $0.3 \mathrm{~g}$ of TTA-C $18 \mathrm{~g}$, was put into a $50 \mathrm{~cm}^{3}$ stoppered glass tube. In the case of $\mathrm{Co}^{2+}$, to prevent to oxidation of $\mathrm{Co}^{2+}$ to $\mathrm{Co}^{3+}, 1.0 \times 10^{-2} \mathrm{~mol} \mathrm{dm}^{-3}$ ascorbic acid was added to the solution as a reductant. The stoppered glass tubes were shaken a few times each day to reach to reaction equilibrium (within $36 \mathrm{~h}$ ) at $298 \mathrm{~K}$. After the reaction was complete, the mixed solutions were filtered. The concentration of metal ions in the aqueous solutions was determined by ICP$\mathrm{AES}$ and the $\mathrm{pH}$ value of the aqueous phase was measured. 


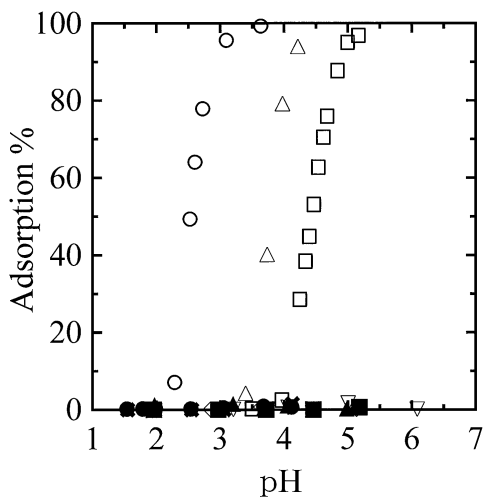

Fig. 1 Adsorption of divalent transition metal ions as a function of to $\mathrm{pH}$ with silica gel, $\mathrm{C} 18 \mathrm{~g}$ and TTA-C18g. Silica gel: $\mathbf{\square}, \mathrm{Co}^{2+} ; \boldsymbol{\Lambda}$, $\mathrm{Ni}^{2+} ; \bullet, \mathrm{Cu}^{2+} . \mathrm{C} 18 \mathrm{~g}: \diamond, \mathrm{Co}^{2+} ; \nabla, \mathrm{Ni}^{2+} ; \times, \mathrm{Cu}^{2+}$. TTA-C18g: $\square, \mathrm{Co}^{2+}$; $\triangle, \mathrm{Ni}^{2+} ; \mathrm{O}, \mathrm{Cu}^{2+}$.

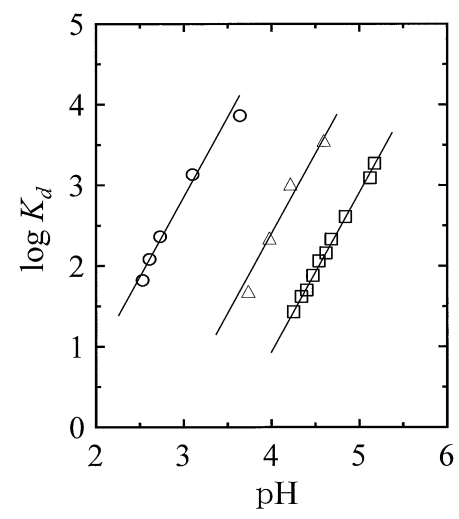

Fig. 2 Distribution coefficient of divalent transition metal ions ( $\square$, $\mathrm{Co}^{2+} ; \triangle, \mathrm{Ni}^{2+} ; \mathrm{O}, \mathrm{Cu}^{2+}$ ) as a function of to $\mathrm{pH}$ with TTA-C18g. The slopes of these lines are +2 .

\section{Results and Discussion}

As described in the introduction, since $\mathrm{C} 18 \mathrm{~g}$ particles aggregated due to hydrophobicity in the aqueous phase, it was impossible to use normal $\mathrm{C} 18 \mathrm{~g}$ as a carrier of the TTA chelating agent. TTA-C18g made from the conventional-size $\mathrm{C} 18 \mathrm{~g}$ $(<0.053 \mathrm{~mm})$ did not quantitatively adsorb the metal ions in the aqueous solution. We successfully synthesized large particles $(0.5-1.0 \mathrm{~mm})$ of TTA-C18g, which prevented particle aggregation. Meanwhile, silica gel that had not bonded with an octadecyl group was not able to retain TTA molecules. The amount of TTA retained on $\mathrm{C} 18 \mathrm{~g}$ was found to be $0.19 \pm 0.01$ mmol g-1 This value was the average of three measurements via the flask combustion method. ${ }^{5}$

Since divalent metal ions $\left(\mathrm{Co}^{2+}, \mathrm{Ni}^{2+}, \mathrm{Cu}^{2+}\right)$ were used for this study, the reaction equation can be expressed as

$$
\mathrm{M}^{2+}+2 \mathrm{HR}_{(\mathrm{C} 18 \mathrm{~g})} \Longleftrightarrow \mathrm{MR}_{2(\mathrm{C} 18 \mathrm{~g})}+2 \mathrm{H}^{+},
$$

where HR and $\mathrm{M}^{2+}$ represent the TTA retained on $\mathrm{C} 18 \mathrm{~g}$ and the divalent transition metal ion, respectively. The subscript $\mathrm{C} 18 \mathrm{~g}$ denotes the species on the solid phase. The distribution coefficient $\left(K_{\mathrm{d}}\right)$ was calculated for Eq. (1) as follows:

$K_{\mathrm{d}}=$ moles metal ion per $1 \mathrm{~g}$ of TTA-C $18 \mathrm{~g} /$ moles metal ion per $1 \mathrm{~cm}^{3}$ of solution. Figure 1 shows a plot of to adsorption percentage of metal ions onto silica gel C18g and TTA-C18g,
Table 1 The $\mathrm{pH}_{1 / 2}$ values of divalent transition metal ions $\left(\mathrm{M}^{2+}\right)$ with TTA-C18g, SE and SE-C18g systems

\begin{tabular}{llll}
\hline \multicolumn{1}{c}{$\mathrm{M}^{2+}$} & $\mathrm{Co}^{2+}$ & $\mathrm{Ni}^{2+}$ & $\mathrm{Cu}^{2+}$ \\
\hline $\mathrm{TTA}^{2+} \mathrm{C} 18 \mathrm{~g}$ & 4.5 & 3.8 & 2.5 \\
$\mathrm{SE}^{\mathrm{a} *}$ & 5.5 & 5.2 & 2.8 \\
$\mathrm{SE}^{\mathrm{c} C 18 \mathrm{~g}^{\mathrm{b} * *}}$ & $-^{\mathrm{c}}$ & $-^{\mathrm{c}}$ & 2.7 \\
\hline
\end{tabular}

a. Aqueous phase $\left(1 \mathrm{~cm}^{3}\right): 1.0 \times 10^{-5}$ to $1.0 \times 10^{-4} \mathrm{~mol} \mathrm{dm}^{-3} \mathrm{M}^{2+}$ and $0.1 \mathrm{~mol} \mathrm{dm}^{-3} \mathrm{KNO}_{3}$. Organic phase $\left(5 \mathrm{~cm}^{3}\right)$ : nitrobenzene containing $0.01 \mathrm{~mol} \mathrm{dm}^{-3}$ of TTA. *See Ref. 7.

b. Aqueous phase $\left(10 \mathrm{~cm}^{3}\right): 1.0 \times 10^{-4} \mathrm{~mol} \mathrm{dm}^{-3} \mathrm{M}^{2+}$ and $0.1 \mathrm{~mol} \mathrm{dm}^{-3}$ $\mathrm{NaNO}_{3}$. Organic phase $\left(10 \mathrm{~cm}^{3}\right)$ : cyclohexane containing $0.01 \mathrm{~mol}$ $\mathrm{dm}^{-3}$ of TTA. C18g (<0.053 meshes): $0.5 \mathrm{~g}$. **See Ref. 3 . c. - : not extracted.

versus $\mathrm{pH}$ of the aqueous solutions. Figure 1 shows that the TTA-C18g has the ability to adsorb metal ions, whereas the silica gel and $\mathrm{C} 18 \mathrm{~g}$ have no adsorption ability in this $\mathrm{pH}$ range. Figure 2 gives plots of $\log K_{\mathrm{d}}$ versus $\mathrm{pH}$ for the aqueous solutions. The solid lines in this figure show plots with a slope of +2 . From these results, the reaction is well expressed by Eq. (1) for the divalent ion systems studied. As can be seen in Fig. 2 , the adsorption selectivity in this system is $\mathrm{Cu}^{2+}>\mathrm{Ni}^{2+}>\mathrm{Co}^{2+}$. The stability constant $\left(\beta_{2}\right)$ can be defined for Eq. (1) as follows:

$$
\beta_{2}=\left[\mathrm{MR}_{2}\right] /\left[\mathrm{M}^{2+}\right]\left[\mathrm{R}^{-}\right]^{2} .
$$

The stability constants have been reported to be $\log \beta_{2}=16.3$, 15.3 and 14.9 for $\mathrm{Cu}^{2+}, \mathrm{Ni}^{2+}$ and $\mathrm{Co}^{2+}$, respectively. ${ }^{6}$ The selectivity of our system is in agreement with the order of the stability constant of the above metal ions with TTA.

Table 1 gives the $\mathrm{pH}$ values of the half-extraction and halfadsorption $\left(\mathrm{pH}_{1 / 2}\right)$ for the TTA-C18g, SE and SE-C18g systems. The results given in the table show that $\mathrm{Co}^{2+}$ and $\mathrm{Ni}^{2+}$ could not be extracted by the SE-C18g method using the lower polarity solvent, toluene. These metal ions were extracted in the SE system using TTA in nitrobenzene, with higher polarity. The maximum value of adsorption for $\mathrm{Co}^{2+}$ was $96 \%$ (Fig. 1). The values for $\mathrm{Cu}^{2+}$ and $\mathrm{Ni}^{2+}$ were more than $96 \%$ in the TTA-C18g system.

The difference in to $\mathrm{pH}_{1 / 2}$ value for the TTA-C18g system between $\mathrm{Ni}^{2+}{ }_{-} \mathrm{Co}^{2+}$ was 0.7 , whereas that of the $\mathrm{SE}$ system was only 0.3 . This result shows that our TTA-C18g system has better mutual selectivity for $\mathrm{Ni}^{2+}-\mathrm{Co}^{2+}$ than the $\mathrm{SE}$ system using TTA in nitrobenzene.

This new method has the advantage of a chelating agent that can be used effectively to remove metal ions from an aqueous solution without organic solvents. It can be expected in a reduction of the amount of toxic solvent used.

\section{References}

1. F. Hagemann, J. Am. Chem. Soc., 1950, 72, 768.

2. Y. Komatsu and H. Kokusen, Japan Patent, 2001, 3374172.

3. T. Shimizu, H. Kokusen, S. Tsurubou, M. Sekita, and Y. Komatsu, J. Ion Exch., 2003, 14(Suppl.), 369.

4. H. Ogawa, T. Koh, K. Taya, and T. Chihara, J. Catal., 1994, 148, 493.

5. W. Schöniger, Mikrochim. Acta, 1955, 123.

6. The Japan Society for Analytical Chemistry, "Bunseki Kagaku Data Book", 4th ed., 1994, Marusen, 94.

7. N. Hirayama, M. Deguchi, H. Kawasumi, and T. Honjo, $J$. Ion Exch., 2003, 14(Suppl.), 345. 